\title{
The Effectiveness of Goldstein's Social Skillstreaming Model on Social Skills of Special Education Pre-Service Teachers at Najran University
}

\author{
Ragea Mohammed Alqahtani \\ Department Of Special Education, Najran University, Kingdom of Saudi Arabia
}

Tel: 966-540-226-220 E-mail: rmalqahtani@nu.edu.sa

Received: March 2, 2016 Accepted: April 4, 2016 Published: April 5, 2016

doi: 10.5296/jsss.v3i2.9140ＵRL: http://dx.doi.org/10.5296/jsss.v3i2.9140

\begin{abstract}
The purpose of the study was to measure the effectiveness of the Goldstein's social skill streaming model based on the special and general pre-service teachers' knowledge about controlling their emotions in conflict situations. A review of previous pieces of literature guided the design and measurement of the effectiveness of the approach to the control of emotions. The teachers were assessed using the coping strategy, adult anger, and Goldstein's skill streaming inventories. Lastly, the paper provides various recommendations on the sensitization of the Goldstein's Social Skill streaming model to both the special and pre-service teachers to promote their knowledge about controlling emotions in conflicts.
\end{abstract}

Keywords: Emotional control, Goldstein social skillstreaming model, Modeling technique, Self-as-a-model, Self-efficacy, Self-regulation

\section{Introduction}

The social skills' training is one of the effective programs that have been utilized as intervention plan for developing social skills and behavior disorders. Since it has been used as the effective training program for developing social skills and behavior for students with disabilities, it may be effective for developing the social skills of teachers whether in classrooms or elsewhere. According to Quinn et al. (1999), the training of social skills' has been used for the development of the behavior disorders especially in the students who exhibit the behavior disorders. People with variety disabilities and ages can receive the positive impact from social skills training, and it supports those people to act on social cues. (Carter, 1998). The social skill training includes four main components such as: 1) Instructions;2) Modeling;3) Rehearsing;4) Transfer of training (Godstein, Sprafkin, Gershaw, 
\& Klein, 1980).

Instructions involve specifically describing the behaviors that must be occurred (Miltenberger, 2008). Modeling involves showing the learner how to act the desired behavior. During rehearsal, the learner carries out the behavior with a trainer providing feedback in the form of praise for executing the behavior accurately and correction for parts that have been executed inaccurately (Miltenberger, 2008). Finally, the trainer will act the desired behavior in a stable manner in class, home, and other places (Godstein et al., 1980). This study focuses on showing how the social skills training assists pre-service teachers to control their emotions in conflict situations especially when they work with students who exhibit behavior disorders. The used social skills training in this study includes one model that is Goldsteins' Social Skills model.

\subsection{Purpose Statement}

The purpose of this study is to test the hypothesis that pre-service special education teachers, when being taught a research-based teaching model for Social Skill streaming (McGinnis \& Goldstein, 2005), can personalize the steps as well as consider them as part of their future teaching repertoire. The study is three-fold to investigate: 1) teachers' knowledge of the social skills steps they use to control their own emotions during conflict situations; 2) teachers' self-perception of their coping strategies to control their own emotions during conflict situations; and 3) teachers' perceived use of the Goldstein Social Skillstreaming Model (2005). It will assist to improve their teaching of students with emotional and behavioral disorders to control their emotions during conflict situations.

\subsection{Research Questions}

Is there a change in score from pre to post assessment using Goldstein Skillstreaming Inventory after training of Goldstein's skillstreaming model?

\section{Literature Review}

Teachers' beliefs should be investigated to understand how they develop, including the similarities between beliefs and practices, and the way they can be changed. We deal with teachers' beliefs along with student learning and motivation through answering these questions: What are the definitions and concepts of beliefs? What are the common beliefs that teachers have on student learning and motivation? What changes should we recommend for teachers' beliefs and instructions? This essay forms part of a literature review on several underlying topics of what constitutes the learning process.

Those involved in the learning process in the formal classroom setting have many rules, theories, beliefs, and phenomena to know, and make it a basis for their activities in the classroom (Goldstein \& McGinnis, 1997, p. 13). In a study, Turner, Christensen, and Meyer (2009, p. 361) focused on practicing mathematics teachers in addressing teachers' beliefs, motivation, and learning. Furinghetti and Pehkonen (as cited in Turner et al., 2009, p. 361) indicated that there are two kinds of knowledge, one objective and the other - subjective. Beliefs are subjective and are assumptions or suppositions, whereas knowledge refers to facts we know as truth. Knowledge and beliefs comprise contrast. There are many who disagree with believers, but they meet at a certain point when it comes to knowledge (Wigfield \& Eccles, 2002). 
According Brophy, (2010) suggested by John Dewey about 'catching and holding students' interest that indicated motivational techniques in mathematics classes such as brain teasers, working on computers, and allowing them to perform group works were effective in catching their attention in math subject. However, not in holding their interest that will enable them to achieve significant learning. It is not enough for students to be motivated by allowing them to study along with enjoyable activities. They should know how to work hard and concentrate on the subject matter. According to Brophy (2010), the other thing is that although motivational strategies allow students to enjoy in their classroom activities, it is not an assurance that it can lead to or fulfill the teachers' learning goals.

\subsection{Disruptive Behavior}

In a recent study, $75 \%$ of children who displayed anti-social behavior were brought to highly restrictive and other placement homes. Children exhibiting disruptive behaviors are considered to have school problems (Witt, VanDerHeyden, \& Gilbertson, 2004, p. 438).

\subsection{Modeling Strategy}

Bandura's (Schunk \& Zimmerman, 2007) social cognitive theory states that "human functioning is a series of reciprocal interactions between personal influences (e.g. thoughts, beliefs), environmental features, and behaviors". For example, one's beliefs (known as self-efficacy beliefs) can affect the environment; this means that efficacious students who try to write an essay or literary work in a noisy environment will try to redouble their efforts by deep concentration to avoid distractions (Zimmerman, 1998; Shell, Murphy, \& Bruning, 1989).

Conversely, the environment can also affect an individual's behavior. Students who receive positive feedback and encouraging words from teachers will feel efficacious and try to work harder to get higher grades (Stewart, Myers, \& Culley, 2010, p. 46). Teachers can create an inspiring environment for students to write or study well, allowing students to have a fruitful time to write and revise their work (Schunk \& Zimmerman, 2007, p. 10; Zimmerman, 2000; Wehmeyer, 2007, p. 4; Sexton, Harris, \& Graham, 1998).

Learning effectiveness and retention is an interesting subject when speaking of distance education. Distance education has some risks, for example, social isolation on the part of the learners - he/she is away doing their own job. The student has to be motivated, or he/she could lose interest in the subject matter. Distance education keeps the student away from the rest while it is a fact that we learn through social contact, sharing, and interaction (Ramachandran \& Rahim, 2004, p. 162).

According to Brophy (2010), the key to motivating the minds of students for learning activities is to provide them with powerful ideas, which contain "content structures, reflect major instructional goals, and provide the basis for authentic applications". In conducting important learning, students' cognitive/learning aspects should be motivated to absorb the lesson and not just for the fun and enjoyment of doing it (Brophy, 2010, p. 201).

Additionally, observational learning usually occurs in the ordinary classroom. According to theorists, learning is a result of observing other people. Conditioning is a factor in social learning. Human beings are unique living organisms that have distinct beliefs and attitudes. These unique beliefs and attitudes, including our expectations, influence the way we consume 
knowledge, information, and reinforcers. A reinforcer is the result of our relationship with the environment (Nicholas, 2008, p. 132).

The demands of succeeding lessons may provide different expectations. It is suggested therefore that different types of expectations (that should be realistic ones) should be generated for each particular student (Campbell \& Kyriakides, 2000; Creemers \& Kyriakides, 2008, p. 97).

Bandura writes that self-efficacy beliefs on one's self enable him/her "to learn or perform behaviors" at certain levels (as cited in Schunk, 2003, p. 159). Studies have revealed that self-efficacy in students motivates learning. It is one aspect that predicts their academic motivation and learning (Pajares, 1996; Schunk, 2003, p. 159).

\section{Methodology}

\subsection{The Sample}

The participants in this study will be 20 senior pre-service teachers attending the Najran University (NU) and enrolling in the K-12 teacher preparation programs for special education and general education. Participants will consist of both male and female students. The participants will be volunteers who are randomly divided into either the experimental and control group. The participants of the experimental group will receive training from one program (the Social Skillstreaming Model) while the participants of the control group will receive no training program during the study. All participants will complete pre- and post inventories (Coping Strategies Inventory, Adults Anger Inventory, and Goldstein's Social Skills Inventory). These inventories are regarding emotional control and use of social skills in their daily lives. At the end of the study, each participant will be rewarded a social skills curriculum.

Each participant will receive an email with the explanation of the purpose of the study, main procedures, and duration of the study, risks, benefits, rights, and other important information that will clarify the study for them. Contact information will be provided in the communication as well. Each student who decides to participate in the study will be requested to supply contact information for updating purposes that will be used to administer the pre- and post-inventories electronically. Moreover, the participants will receive the results of the study once it is completed. As mentioned, participants will be provided with the right to withdraw from participation in the study at any time. In contrast, any participant who withdraws from the study will have no rights to neither obtain any special information about the study nor be able to return as a participant in the study later.

\subsection{Variables}

This study will include one independent variable: Goldstein Social Skillstreaming Model (2005). The independent variable is the Goldstein Social Skillstreaming Model, which is operationally defined as the training, or treatment program that will be provided to the experimental group during the study (approximately three months). The main goal of this variable will be to deliver definitions of the social skills, their characteristics, how the pre-service teachers implement them in conflictive situations, and the importance of these social skills for the pre-service teachers' life, especially when they work at schools. In addition, the experimental group will receive a lecture about skills to control emotions for 
twenty minutes weekly.

The dependent variable is the pre-service teachers' self-perceived knowledge of social skills for controlling their emotions in conflictive situations and teaching steps for controlling emotions during conflictive situations to students with emotional and behavioral disorders (measured by Goldstein Skillstreaming Inventory).

\subsection{Instruments}

Goldstein's Social Skillstreaming Inventory. The pre-service teachers in both the experimental and control groups will complete pre- and post- test of the Goldstein's Social Skillstreaming Inventory. Goldstein Skillstreaming Inventory will be created as a website. The link will be sent via e-mail to all participants of the study. Each participant will have to click on the link, complete the inventory, and then submit it electronically. Social Skillstreaming Inventory will assist via the identification of the differences between the participants' knowledge of controlling emotional skill in conflictive situations. It will also contribute to the definition of pre-service needs for controlling their emotions in this study (Goldstein \& McGinnis, 1997).

The reliability of social skill is temporal stability that is going test and retest. Each group will complete pre- and post-tests the social skillstreaming checklist. Therefore, the researcher must be careful when implementing the test-retest approach ( $\mathrm{Yu}, 2005)$. The validity is a faced validity because it looks the operationalization and identifies whether "on its face" is a good translation of the construct (William, 2006).

\subsection{Design}

This study will measure the effectiveness of Goldstein' Social Skillstreaming Model on the special and general pre-service teachers' knowledge about controlling their emotion skills in conflictive situations. It is an experimental study and, as it has been mentioned, will consist of two groups (experimental group and control group). Each group will be formed of 10 special education pre-service teachers.

The experimental group will complete the pre/post test of the Skillstreaming Inventory that contributes to showing the differences of the pre-service teachers' knowledge of their own social skills. In addition, this group will receive training or treatment (Goldstein's Social Skillstreaming Model) to develop their knowledge and perception to control their emotions. The pre-service teachers will attend lectures to gain information that will clarify the most influential social skills and how to implement them in conflict situations. They will receive this model twice a week. The control group will obtain no training or treatment.

The control group will not receive the training or treatment programs to develop their social skills. The only procedures they will complete are the pre- and post-tests of the Skillstreaming Inventory.These procedures will identify the positive effect of the Goldstein Social Skills Model on the knowledge of pre-service teachers who either are in the experimental or control group. Moreover, these inventory will measure the differences of pre-service teachers' knowledge from the beginning and ending of the study and identify if there are any differences between their knowledge of controlling emotions in conflictive situations even if they do not receive any treatment program. 


\subsection{The Procedures of Providing Training Program}

At the beginning of the study, an e-mail will be sent via the Electronic Najran Emails system to all students who are considered pre-service teachers. The e-mail will include a message regarding the purpose, procedures, and goals of the study. In addition, the pre-service teachers will be involved in a special lecture that will provide an explanation of the purpose, method, procedures, risks, and costs of the study as well as their rights. Each participant will sign a consent form indicating that he or she understands the study and rights of the participant.

This study will include three stages: (a) before the implementation of the Goldstein's Social Skillstreaming Model training program, (b) during the implementation of the training program, and (c) after implementation of the training program. The first stage will consist of each participant's completion of the pre-test for Goldesten Skillstreaming Inventory which is utilized in the study. Data will be collected and organized. The second stage will consist of implementing the training program. In this stage, the implementation of the training program will be conducted over a period of ten weeks. It will focus on the needs of pre-service teachers to control their emotional skills in conflictive situations. The Social Skillstreaming checklist will be utilized to identify the social skills that need to be developed (Goldstein \& McGinnis, 1997).

Only the pre-service teachers in the experimental group will receive the training program. They will be provided a 45-minute session of Goldstein Social Skillstreaming Model per week for 10 weeks and a 40-mintue session of Self-as-a-Model training per week for 10 weeks. All sessions will be conducted in a room at the Najran University. A weekly attendance checklist will be completed for each session each week.

The participants will attend a lecture on each social skill to gain information about what is it, why it is essential, and how to implement it in conflictive situations. In the same week, they will watch a videotape related to the same social skill, which will show the pre-service teachers how to implement that social skill in the classroom, especially with students who have behavioral disorders and in public places. Moreover, the pre-service teachers will complete a self-report by answering three to four questions about what they have learned about controlling their emotions in the conflicting situation by using social skills, how they feel about the provision of the program, and what they understand concerning taking control over emotions in conflictive situations. Then they will respond to open questions that are related to what they have learned from the two sessions.

The participants will receive feedback on their understanding and knowledge from the lectures and videotapes related to the social skill utilized in controlling emotions in the conflictive situation, especially in classrooms. The above process will be completed by each participant of the experimental group as weekly homework and will be submitted to the research via e-mail. Upon receipt of each e-mail, the researcher will provide each participant with feedback related to his or her experience with the training program.

The third stage will consist of completing the post-test of Goldstein Skillstreaming Inventory at the end of the training program. All participants of both groups will complete the post-test that will reflect their knowledge and perception of taking control over their emotions in 
conflictive situations by utilizing the social skills. Upon completion of the checklists, data analysis will be conducted to identify the differences between each participant's knowledge of controlling emotions by utilizing the social skills before and after implementation of the study. Moreover, differences between each group and efficient training programs will be analyzed.

\subsection{Statistical Design}

The collected data will be organized into three categories based on the research question.

Q1 Is there a change in score from pre- to post-assessment using the Adult Anger Inventory after training using Goldstein's Social Skillstreaming Model?

The statistical design will include one two-way ANOVA table. One ANOVA table will be conducted for the analysis of the data that are collected from the inventory (Goldstein's' Social Skillstearming Inventory).

\section{Analysis of Data}

\subsection{Research Question}

Is there a difference amongst the pre-service teachers' knowledge about their social skill use according to the pre/post Goldstein skill-streaming inventory scores after training with the Goldstein's Social Skill-streaming Model?

\subsection{Measurement Tool}

The researcher used the Goldstein's skill-streaming inventory scores to identify the differences that existed between the pre and post assessment. A rating checklist was used to assess and determine the frequency at which the participants reported the usage of specific social skills. The checklist was issued as a pre-and-post assessment. At the pre-assessment stage, the scores were used to note the most informed skills shown during the experiment. Both the pre and post assessment scores assisted by noting the differences and effectiveness of the Goldstein's skill-streaming model due to the change in the growth of the teachers' perceived knowledge of emotional control of conflict situations. Teachers who had used the skills often developed confidence in handling conflict solutions.

After the pre and post assessment, the participants were rated according to the use of their skills. They were provided with a 45-minute session of the Goldstein social skill-streaming model per week. This process continued for ten weeks. A weekly 40-mintue session of the self-as-a-model training was also provided for ten weeks. The pre and post assessment before training indicated lower scores regarding the use of the perceived skills to control emotions in conflict situations. The lowest ranking was noted in the understanding of one's feelings that had a difference of 2 between the pre and post assessment. Avoidance of problems had a difference of 3 between the evaluations. A different of 11 between the pre and post assessment was noted in the formulation of a solution to the conflict.

The post-assessment scores after training (shown in Table 3a (ii)) indicated an increase in their perceived use of the social skills in conflict situations with the highest improvement shown in the avoidance of conflicts. In this case, paying attention to dealing with the conflict was also rated high. Both skills scored a difference of 19 between the pre- and post-assessment after the training. The least difference occurred in the skills pertaining dealing with the people's anger that had a difference of 12 between the pre- and 
post-assessment (see Appendix C).A comparison between the $p$-values of the control and experiment groups after the training where the control group was excluded indicated the effectiveness of Goldstein's skill-streaming model. The experiment had a $p$-value of 0.358992 while the control scored 0.012496. It can be concluded that the Goldstein's skill-streaming training model is effective in improving the skills of controlling emotions amongst teachers involved in conflict situations. Discussion Goldstein's Skill-Streaming Training Technique.

The respondents were trained in the Goldstein's skill-streaming model whilst focusing on the behaviors and feelings that guided the formulation of solutions to conflict situations. The participants were taught the target behaviors such as using words and certain actions for expression to limit the instances of intimidation. Others included replacement behaviors such as support, positive actions and words, effective ways of solving conflicts. The move to measure the effectiveness of the Goldstein's Model increased the respondents' knowledge about social skills. The result was a perceived replacement of the negative behaviors towards conflicts. Changing behaviors were observed using other techniques such as the Coping Strategy, Adult Anger, and Goldstein's inventories to note any improvement after the Goldstein's skill-streaming model lecture (Elksnin \& Elksnin, 2003).

\subsubsection{Goldstein's Skill-Streaming Inventory}

The Goldstein's skill-streaming inventory elaborated four components that included modeling, role-playing, performance feedback, and training. The assessment of the experimental group indicated moderately high skills that the respondents applied to conflict situations. After the training, the respondents improved their perceived skills in dealing with conflict situations as indicated by a $p$-value of 0.358992 and 0.012496 for the experiment and control groups respectively. The probability that the respondents were likely to use the skills in different conflict situations was high. This study closely related to the one conducted by Maag (2006) that focused on the social skills among children.

\section{Recommendations}

Based on the analysis of the effectiveness of the Goldstein's Skill-streaming Model, it was recommended to provide a better faculty for teacher development in social skills to heighten the control of emotions in cases that involve conflicts;

The methods should also be used together to improve the feasibility of the conflict resolving processes. For instance, the Goldstein's social skill-streaming model should be integrated with the copying inventory stress strategies to reinforce the skills of controlling emotions and attitudes towards conflicts.

\section{Conclusion}

The study entailed measuring the effectiveness of the Goldstein's social skill-streaming model amongst the special and general pre-service teachers' knowledge about controlling their emotion skills in conflicts. The results indicated that training teachers in the Goldstein's skill-streaming model improved the skills used in conflict situations. Most institutions use various methods to train students how to control emotions and anger by seeking the required skills needed in conflict situations. Most of these institutions combine the methods for successful outcomes. 


\section{Acknowledgement}

I would like to express my sincere gratitude to Allah (My God), the most gracious

and most merciful for enabling and helping me to complete this study my Ph.D. successfully, In completing this study, I would like to extend my deep thanks, gratitude and appreciation to everyone who contributed to my successful completion. Foremost, I would like to express my sincere thanks to my great supportive my Wife for her encouragement and support. She is a very supportive person. Thank you so much for everything, you are my achievement companion. I would like to thank my boys, Mohammed and Hamad, for their quiet when I was working on my study.

\section{Reference}

Bandura, A. (1997). Self-efficacy: The exercise of control. New York: Freeman.

Brophy, J. (2010). Motivating students to learn. New York: Routledge.

Campbell, R. J., \& Kyriakides, L. (2000). The national curriculum and standards in primary schools: a comparative perspective. Comparative Education, 36(4), 383-395. http://dx.doi.org/10.1080/713656661

Carter, J. (1998). Social Skills Training. In Beyond Behavior Modification: A Cognitive-Behavioral Approach to Behavior Management in the School (3rd edition). Austin, Texas: Pro-Ed

Creemers, B. P. M., \& Kyriakides, L. (2008). The dynamics of educational effectiveness: a contribution to policy, practice and theory in contemporary schools. United States and Canada: Routledge.

Elksnin, L., \& Elksnin, N. (2003). Fostering social-emotional learning in the classroom. Education, 124(1), 63.

Goldstein, A. P. (1999). The prepare curriculum: teaching prosocial competencies (revised edition). United States of America: Research Press.

Goldstein, A. P., \& McGinnis, E. (1997). Skillstreaming the adolescent: new strategies and perspectives for teaching prosocial skills (revised edition). United States of America: Research Press.

Maag, J. (2006). Social skills training for students with emotional and behavioral disorders: A review of reviews. Behavioral Disorders, 32(1), 4-17.

Miltenberger, R. G. (2008). Behavioral skills training procedures. In Behavior Modification: Principles and Procedures Thomson Higher Education, Belmont, CA, 251-265.

Nicholas, L. (2008). Introduction to psychology second edition. United States of America: UCT Press.

Quinn, M. M., Kavale, K. A., Mathur, S. R., Rutherford, R. B. Jr., \& Forness, S. R. (1999). A Meta-Analysis of Social Skill Interventions for Students with Emotional or Behavioral Disorder. Journal of Emotional and Behavior Disorders, 7(1), 54-64. http://dx.doi.org/10.1177/106342669900700106

Ramachandran, S. D., \& Rahim, H. A. (2004). Meaning recall and retention: the impact of the translation method on elementary level learners' vocabulary learning. RELC Journal, 35, 161. 
http://dx.doi.org/10.1177/003368820403500205

Schunk, D. H. (2003). Self-efficacy for reading and writing: influence of modeling, goal setting, and self-evaluation. Reading \& Writing Quarterly, 19, 159-172. http://dx.doi.org/10.1080/10573560308219

Schunk, D. H., \& Usher, E. L. (2011). Assessing self-efficacy for self-regulated learning. In B. J. Zimmerman, \& D. H. Schunk (Eds.), Handbook of self-regulation of learning and performance: educational psychology handbook series. New York, New York; UK: Routledge.

Schunk, D. H., \& Zimmerman, B. J. (2007). Influencing children's self-efficacy and self-regulation of reading and writing through modeling. Reading \& Writing Quarterly, 23, 7-25. http://dx.doi.org/10.1080/10573560600837578

Sexton, M., Harris, K. R., \& Graham, S. (1998). Self-regulated strategy development and the writing process: Effects on essay writing and attributions. Retrieved from: Business Source Complete database, Exceptional Children, 64, 295-311

Shell, D. F., Murphy, C. C., \& Bruning, R. H. (1989). Self-efficacy and outcome expectancy mechanisms in reading and writing achievement. Journal of Educational Psychology, 81, 91-100. http://dx.doi.org/10.1037/0022-0663.81.1.91

Stewart, T. L., Myers, A. C., \& Culley, M. R. (2010). Enhanced learning and retention through "writing to learn" in the psychology classroom. Teaching of Psychology, 37, 46-49. http://dx.doi.org/10.1080/00986280903425813

Turner, J. C., Christensen, A., \& Meyer, D. K. (2009). Teachers' beliefs about student learning and motivation. In L. J. Saha, \& A. G. Dworkin, A. G. (Eds.), International handbook of research on teachers and teaching. United States of America: Springer Science+Business Media, LLC.

Yu, C. H. (2005). Test-retest reliability. In K. Kempf-Leonard (Ed.). San Diego, CA: Academic Press. http://dx.doi.org/10.1016/b0-12-369398-5/00094-3

Wehmeyer, M. L. (2007). Promoting self-determination in students with developmental disabilities. New York: Guilford Press.

Wigfield, A., \& Eccles, J. S. (2002). The development of competence beliefs, expectancies for success, and achievement values from childhood through adolescence. In A. Wigfield, \& J. S. Eccles (Eds.), Development of achievement motivation (pp. 91-120). San Diego: Academic Press. http://dx.doi.org/10.1016/B978-012750053-9/50006-1

Witt, J. C., VanDerHeyden, A. M., \& Gilbertson, D. (2004). Instruction and classroom management: prevention and intervention research. In R. B. Rutherford, M. M. Quinn, \& S. R. Mathur (Eds.), Handbook of research in emotional and behavioral disorders. New York, New York: Guilford Press.

Zimmerman, B. J. (1998). Developing self-fulfilling cycles of academic regulation: An analysis of exemplary instructional models. In D. H. Schunk, \& B. J. Zimmerman (Eds.), Self-regulated learning: From teaching to self-reflective practice (pp. 1-19). New York: Guilford Press.

Zimmerman, B. J. (2000). Attaining self-regulation: A social cognitive perspective. In M. 


\section{Macrothink}

Journal of Social Science Studies

ISSN 2329-9150

2016, Vol. 3, No. 2

Boekaerts, P. R. Pintrich, \& M. Zeidner (Eds.), Handbook of self-regulation (pp. 13-39). San Diego: Academic Press. http://dx.doi.org/10.1016/B978-012109890-2/50031-7

Zimmerman, B. J. (2001). Theories of self-regulated learning and academic achievement: an overview and analysis. In B. J. Zimmerman, \& D. H. Schunk (Eds.), Self-regulated learning and academic achievement: theoretical perspectives (2nd ed., pp. 1-37). Mahwah, NJ: Erlbaum.

\section{Copyright Disclaimer}

Copyright for this article is retained by the author(s), with first publication rights granted to the journal.

This is an open-access article distributed under the terms and conditions of the Creative Commons Attribution license (http://creativecommons.org/licenses/by/3.0/). 